\title{
The Green Composites: Millet Husk Fiber (MHF) Filled Poly Lactic Acid (PLA) and Degradability Effects on Environment
}

\author{
Abba Alhaji Hammajam ${ }^{*}$, Abubakar Mohammed El-Jummah"1, Zahari Nur Ismarrubie² \\ ${ }^{1}$ Department of Mechanical Engineering, University of Maiduguri, Maiduguri, Nigeria \\ ${ }^{2}$ Department of Mechanical and Manufacturing Engineering, Universiti Putra Malaysia, Serdang, Selangor, Malaysia \\ Email: ^hammajam92@gmail.com
}

How to cite this paper: Hammajam, A.A., El-Jummah, A.M. and Ismarrubie, Z.N. (2019) The Green Composites: Millet Husk Fiber (MHF) Filled Poly Lactic Acid (PLA) and Degradability Effects on Environment. Open Journal of Composite Materials, 9 , 300-311.

https://doi.org/10.4236/ojcm.2019.93018

Received: May 27, 2019

Accepted: July 9, 2019

Published: July 12, 2019

Copyright $\odot 2019$ by author(s) and Scientific Research Publishing Inc. This work is licensed under the Creative Commons Attribution International License (CC BY 4.0).

http://creativecommons.org/licenses/by/4.0/

\begin{abstract}
This study provides an overview on green composites degradability. Practically, the main drawbacks of using natural fibers are their poor dimensional stability, degradability and high degree of moisture absorption. While, end use of product from natural fiber filled or reinforced composites has become subject of concern to material engineers and scientist. The major properties of natural fiber reinforced polymer composites are greatly dependent on the hydrophilic tendency and dimensional stability of the fibers used, morphology aspect ratio for long fiber, while voids for powder fibers. The effects of chemical treatments on cellulosic fibers that are used as reinforcements for thermoplastics were studied. The chemical source for the treatments is alkalization. The significance of chemically-treated natural fibers is seen through the improvement of mechanical properties. The untreated fiber composites degrade faster in municipal soil compared to treated fiber composites.
\end{abstract}

\section{Keywords \\ Degradability, Composite, Fibers, Poly Lactic Acid, Millet Husk}

\section{Introduction}

Research and advancement on natural fiber composites are continually rising and their function is growing into novel field of usage [1] [2] [3] and [4]. The attributes of natural fibers such as; availability, low density, cost effectiveness, renewability, and biodegradability act as agent in the replacement of usual fillers/reinforcements of composites, like carbon and glass, into the novel alternatives. However, problems associated with the use of synthetics materials force 
legislation to enact law that protects the environment in many countries around the globe [5] [6] and [7]. Also the search for low cost and superior materials in many advanced technologies such as automotive, nautical, building as alternative to synthetic materials has received prompt attention [8]. Therefore, utilization of these fibers can save environment and humanity as it becomes house for microorganism that harbors diseases. In spite of the above listed good attributes of the natural fibers and its composites, there are some hindrances that may reduce their growth into broader use [8] [9] and [10]. However, [11] [12] and [13] have outlined more advantages of using agricultural wastes as fillers in thermoplastic composites such as: availability, cost effectiveness, biodegradability, low energy consumption, low density, high specific properties etc. Most natural fibers from these wastes are used as reinforcements or fillers in polymer composites for creating technology innovative materials as a function of cost [7].

The use of thermoplastic poly lactic acid (PLA) in demanding technology applications has increased in recent time [14]. Due to the attractive properties of high melting point, high density and good chemical inertness, it becomes an important choice for husk, fiber filler, compounding and blending work [15]. Because of composites nature, it can be remelted and recycled for various purposes, thus PLA composites are profitable and environmentally friendly. Although a good work has been done in varieties of areas on agro waste composites, the current literature on millet husk is limited with respect to their composites formations. Thus, this topic forms the basis for this study. The aim of the investigation is to see the degradability possibility of millet husk powder (MHP) fibers as filler poly lactic acid (PLA) composites by soil techniques.

\section{Materials and Methods}

\subsection{Materials}

The millet husks were collected from farm site, dumped after milling at Bulumkutu Kasuwa Area of Maiduguri Borno, Northeastern Nigeria. These husk residues were left in an open air on the farm after harvest. For purpose of this study, $4 \mathrm{~kg}$ of materials were collected one month after the milling on the farm site. The millet husks were initially dried at $105^{\circ} \mathrm{C}$ for $24 \mathrm{hr}$ in an industrial oven for the purpose of removing excess moisture according to ASTM D4442, (2010) standard test procedure. Fibers were chemically treated by using sodium hydroxide $(\mathrm{NaOH})$ or mercerization and milled using pulverizing machine. Poly lactic acid (PLA) grade 2002D was a Nature works LLC (USA) IngeoTM grade, and it was supplied in the form of granules. The properties of the matrix were: density, $1.25 \mathrm{~g} / \mathrm{cm}^{3}$; glass transition temperature $(\mathrm{Tg}), 59^{\circ} \mathrm{C}$; melting point, $152^{\circ} \mathrm{C}$; and melt flow index (MFI), $30.3 \mathrm{~g} / 10 \mathrm{~min}$. PLA undergoes thermal degradation at temperatures above $200^{\circ} \mathrm{C}$ by hydrolysis, lactide reformation oxidative main chain scission, and inter- or intermolecular transesterification reactions that needs processing temperatures above $185^{\circ} \mathrm{C}-190^{\circ} \mathrm{C}$. The millet husk fibers and world millet production outlook are shown in Figure 1, while Table 1 depicts the major producing area of millet per metric tons. 

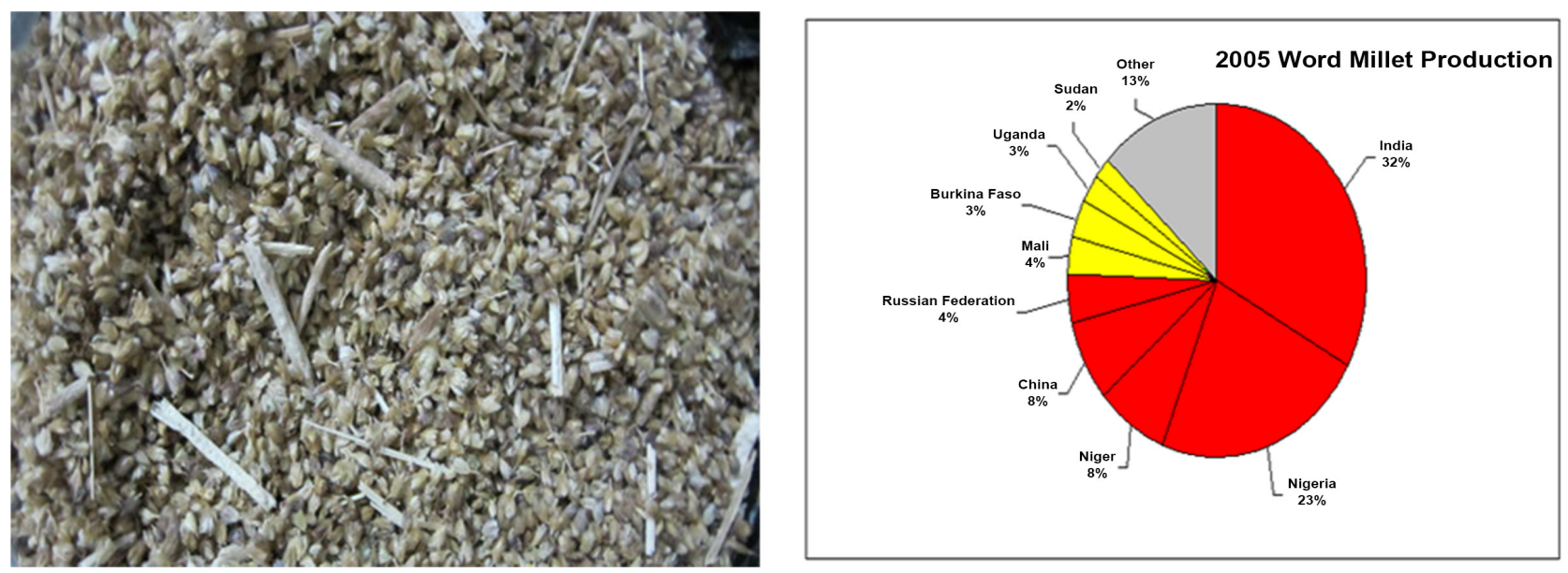

Figure 1. (a) Millet husk fibers and (b) world millet production outlook [28].

Table 1. Major Millet producing areas (Millet Production by Country in 1000 MT) FAO, [29].

\begin{tabular}{ccccccc}
\hline Country & India & Nigeria & Niger & Mali & China & World (estimated) \\
\hline Production (tones) & $11,000.00$ & 5800.00 & 3200.00 & 1600.00 & 1900.00 & $\begin{array}{c}\mathbf{2 3 , 5 0 0} \text { (major) } \\
\mathbf{3 7 , 8 0 0} \text { (estimated) }\end{array}$ \\
\hline
\end{tabular}

\subsection{Rule of Mixtures (ROM)}

This process involved the rules guiding the mixing of fiber and matrix in composites formulations. In this study, the ROM was based on the capacity of the internal mixer (Brabender). Volume of the fiber and matrix was governed by the rule as: ROM:

$$
\begin{aligned}
V_{f}+V_{m} & =1 . \\
V_{m f}+V_{p l a} & =M_{c w}
\end{aligned}
$$

where; $V_{f}$ is volume of fiber, $V_{m}$ is volume of matrix, $V_{m f}$ is volume of millet fiber, $V_{p l a}$ is volume of high density polyethylene, $M_{c w}$ is mixer capacity.

Figure 2 shows the internal mixer and blending process as well as composites pellets of different fiber loadings. Also Table 2 indicates the Formulation of MHP-PLA composites.

\subsection{Biodegradability Test}

Biodegradation is the chemical breakdown of materials by a physiological environment. The test was carried out base on [16] standard test. The expression is frequently applied relative to ecology, waste management, and environmental remediation. Organic material can be degraded aerobically, with oxygen, or anaerobically, without oxygen. Biodegradable polymers may be defined as those that undergo microbial induced chain scission, leading to mineralization, photo degradation, oxidation, and hydrolysis, which can change a polymer during the degradation process. The technique adapted for this study is oven-drying of the soil sample according to [17] standard association of Australia. This process was performed until the soil weight become equilibrium. The soil moisture content $M_{c}$ was determined from the test sample weight before and after drying by using the equation: 


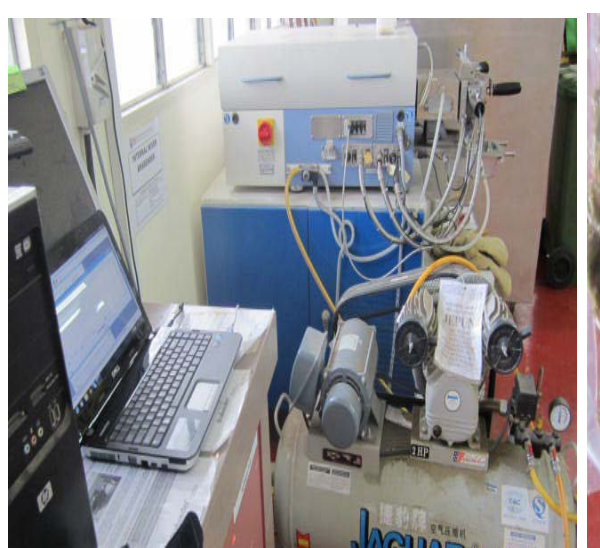

(a)

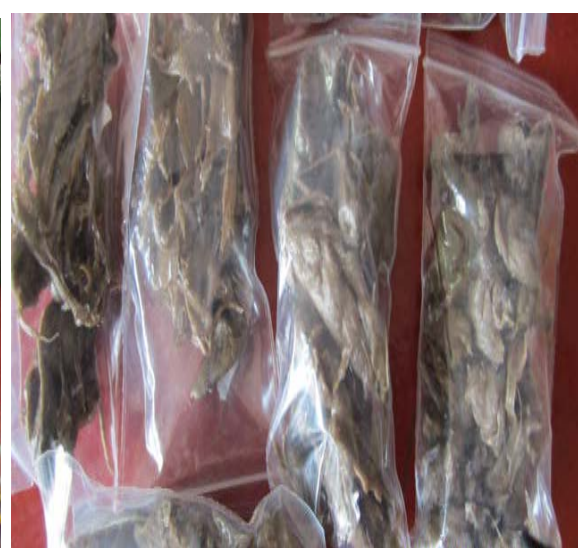

(b)

Figure 2. (a) Blending process PC-Internal mixer; (b) Composites pellets of 40, 30, 20 and 10 percent fiber loadings.

Table 2. Formulation of MHP-PLA.

\begin{tabular}{ccc}
\hline Sample Name & MHP Content (wt \%) & PLA (wt \%) \\
\hline Neat PLA & 0 & 100 \\
MHP-PLA & $10,20,30,40$ & $60,70,80,90$ \\
\hline
\end{tabular}

$$
M_{c}=\frac{W_{2}-W_{3}}{W_{3}-W_{1}} \times 100
$$

where $W_{1}$ is weight of tin $(\mathrm{g}), W_{2}$ is weight of moist soil plus tin $(\mathrm{g}), W_{3}$ is weight of dry soil plus tin (g).

Figure 3 shows Flexural Test specimens $150 \times 12.7 \times 3 \mathrm{~mm}$ used for the investigation of the soil biodegradability. Whereas, Figure 4 Schematic diagrams of tensile and flexural test specimen.

Soil burial tests of all composites of various loadings were buried in containers full of soils by random patterns. Samples were conducted to observe the possible degradation in soil. Biodegradation studies were performed in the metrology laboratory of Federal Polytechnic University Damaturu, Nigeria. After the soil burial tests have been conducted, the composite specimens were collected, washed with water and dried to constant weight in the oven at $105^{\circ} \mathrm{C}$ for $24 \mathrm{hr}$. After that the samples were weighed by using electronic sensitive balance with a precision of $0.1 \mathrm{~g}$ and the weights of the specimens before and after soil burial tests were recorded.

Thereafter, the samples were collected from the container after 120 days for mechanical and microstructure properties analysis. For all the investigations, an average of five (5) test samples was taking. Figure 5 shows the composites samples buried in municipal soil.

\subsection{SEM Microstructural Observations}

The microstructure observations were carried out by using the fractured surface after tensile and impact test of the composites. It was examined using scanning 

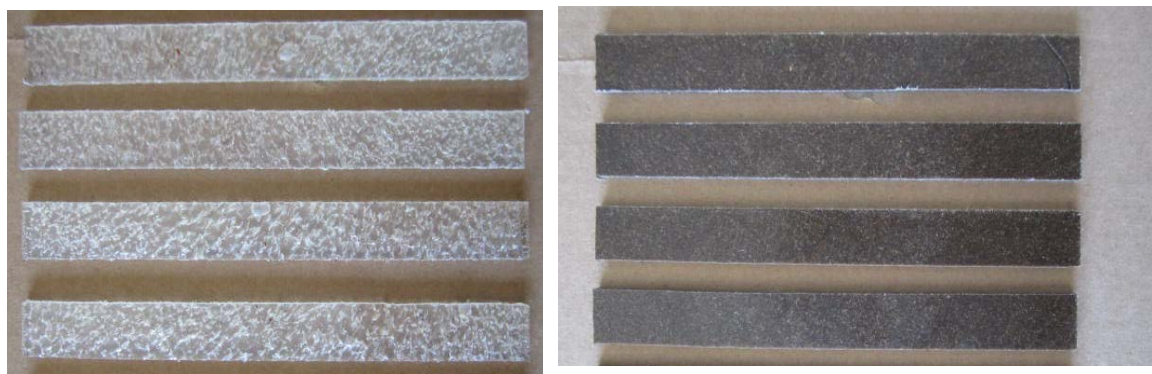

Figure 3. Flexural Test specimens $150 \times 12.7 \times 3 \mathrm{~mm}$.

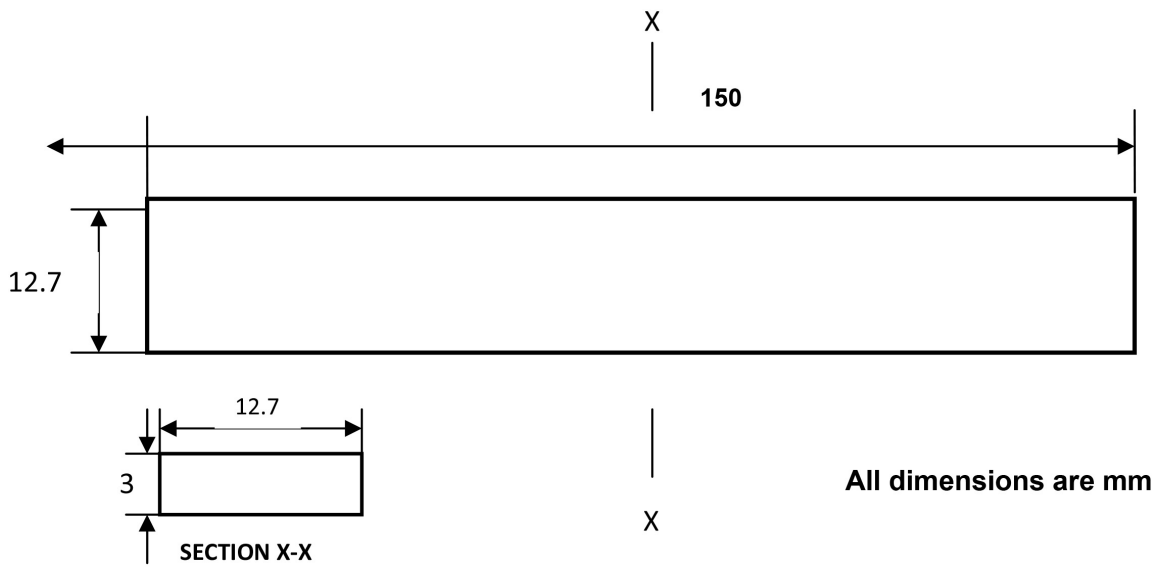

Figure 4. Schematic diagrams of tensile and flexural test specimen.

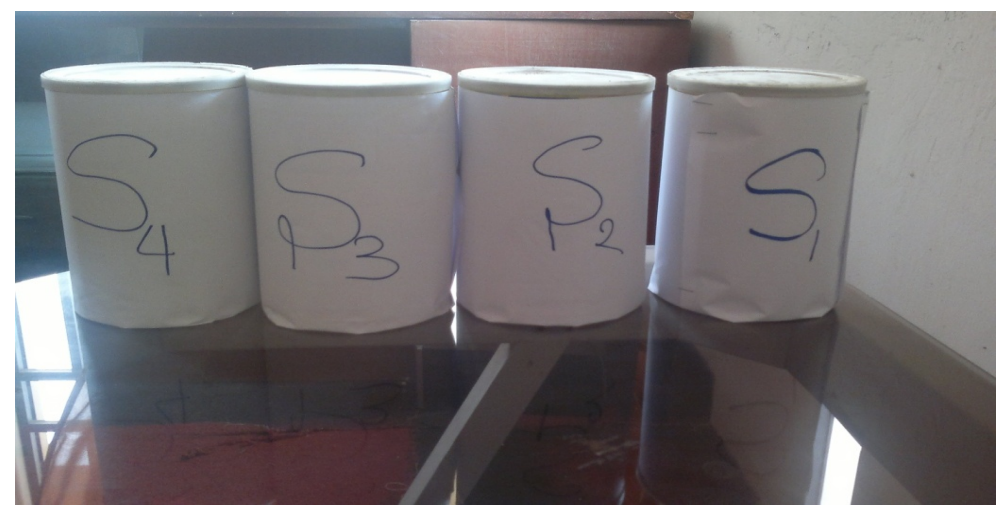

Figure 5. Soil burial tests.

electron microscope (SEM model S-3400 N HITACHI, $20 \mathrm{kV}$ ). All the specimens were coated with layers of gold before SEM examination with the aim to determine the dispersion of the millet husk fiber in the polymer matrix and to study the uniformity of the composite composition or the fiber-matrix adhesion.

\section{Results and Discussion}

\subsection{Biodegradability of MHP-PLA Composites}

Figure 6 depicted the degradation of MHP-PLA composites respectively. The biodegradability of polymer composites was carried out in stages. In this 


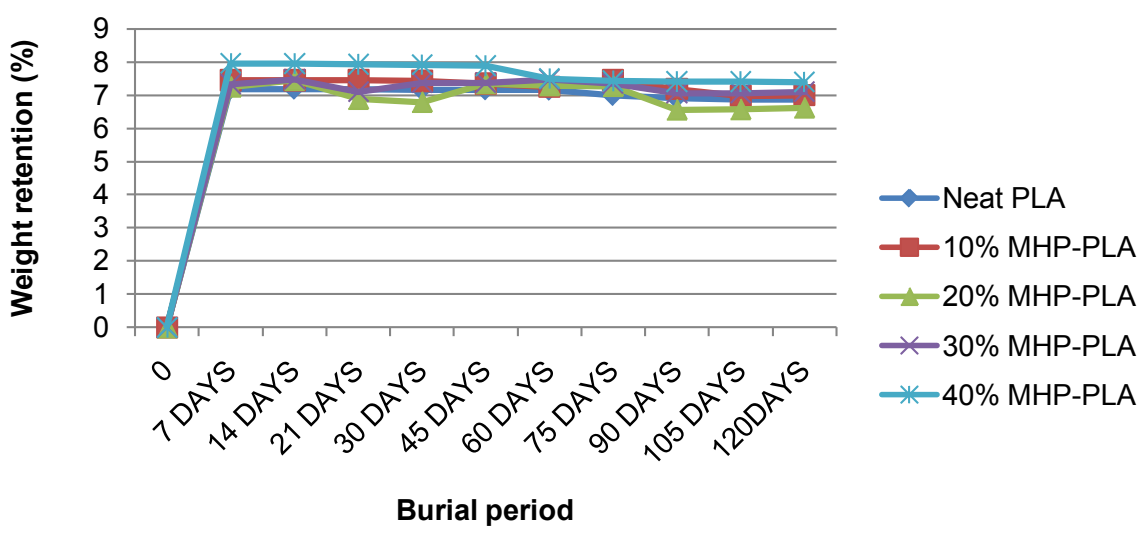

Figure 6. Percentage weight retention as function burial time of MHP-PLA composites soil burial (municipal soil).

investigation, biodegradation of poly lactic acid and its composites go through two procedures. Firstly, hydrolysis of ester linkages took place. This stage may be hastening by acid or base and had tempered by two parameters; moisture and temperature point. It was revealed that at the initial phase of the degradation, none or insignificant microorganisms were concerned. Hydrolysis of PLA samples were preceded by production of water soluble compound and lactic acid. Metabolization via microorganism into carbon dioxide, biomass and water followed afterward. Similar finding was reported by [18]. Particularly PLA are mostly opposed to attack by microorganisms in soil under normal conditions as it was also observed by [19].

Therefore, PLA does not easily degrade in normal municipal soils required an elevated temperature to start the biodegradation. Figure 6 revealed that after eight weeks of burial, the shapes are still intact and degradation happens insignificantly and slowly. Investigation by [20] revealed that PLA bottles made of $96 \%$ L-Lactide showed little degradation due to their highly ordered structure and therefore highly crystalline. Thus relative humidity and temperature plays vital roles in the rate of polymer matrix and it composites degradation [21]. Even though there were no significant changes in shape of the samples, close examination revealed micro pores that could affect mechanical properties of the composites in 30\% and $40 \%$ fiber loadings samples at week 6 and 9 respectively. This attributes indicated progression in degradation of the composites. However, the decompositions in municipal soil progressed more severely with burial time. It was observed that as the molecular weight reduced microbes in the soil start to digest the lower molecular weight of lactic acid generating carbon dioxide and water as similar findings was also reported by [22].

The second phase of the biodegradation was particularly better of MHP-PLA composites over most HDPE composites that were degraded through single phase process involved microbial attack on the polymer main body [23]. PLA was said to have high degradation at elevated temperature between $55^{\circ} \mathrm{C}-70^{\circ} \mathrm{C}$ [24]. But at lower temperature and humidity, stability of PLA products are considered being acceptable [25]. Degradation of high fiber loading are faster and 
severe, this was due to high amount of cellulose and can easily absorb moisture which facilitate the degradations. Figure 7 shows the hydrolysis mechanism of PLA.

\subsection{Visual Examinations of MHP-PLA Composites}

The photographic examinations of the composites samples were investigated during biodegradation. At the initial buried period most composite did not showed sign of decomposition. The surface morphologies of MHP-PLA composites decomposition in soil burial were studied. The visual photographs of PLA composites before degradation indicated suave surfaces. The municipal soil burial after two months the composites surface became rough, and many ravine appeared on the surface of the composites. It was vividly observed the generations of ravines on the surface of the entire composites after 100 days burial in municipal soils but with more pronounce on samples buried in municipal soil. The longer the burial period, the more severe the degradation became as a function of fiber loading. Therefore, the different composites of various fiber loadings established the decomposable attributes as can be seen in Figure 8. While after 21 days burial in municipal soil, the test specimens did not indicated clear signs of degradations for all the fiber loadings. The degradation of the composites shows very little signs as confirm by the weight loss of the composites over a period of time. Similar phenomena were reported by [26] and [22].

The physical observations showed that there was likelihood of changes in attributes such as flexures and brittleness after 45 days of burial time for the PLA composites. It was also observed that the PLA composites degrade faster this was due to nature of the matrix and microbial activities in particular soil. Other possible cause was due to reformation in the nature of the structure of the PLA composites under temperature variations during degradations. Humidity and temperature are considering as major ingredient for biodegradation apart from the degradation period. These factors often affect the characteristics of the composites under investigations. Therefore, it was revealed that increased fiber

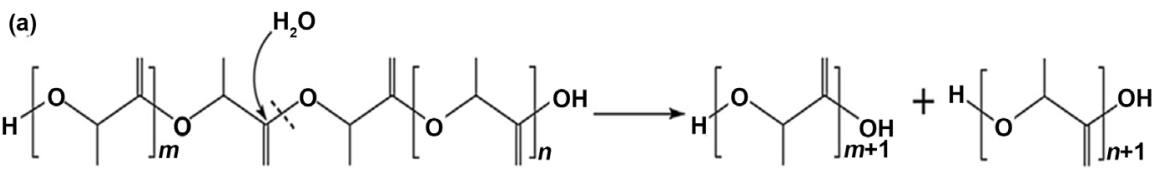

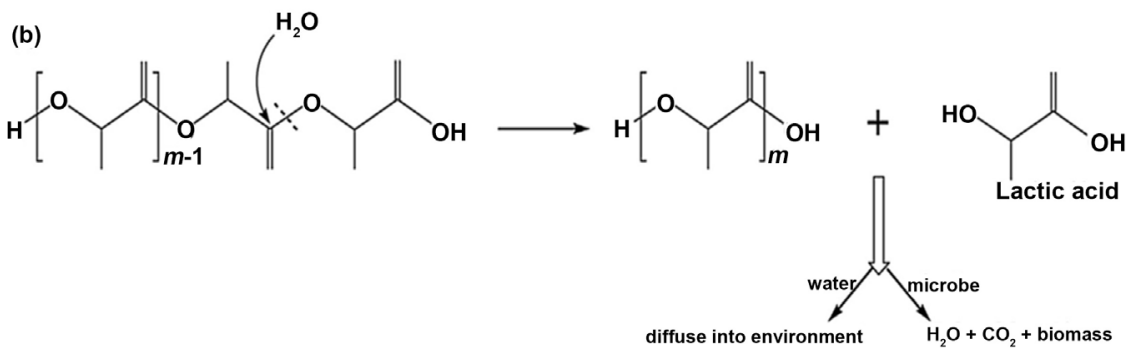

Figure 7. Hydrolysis mechanism of PLA in soil (adapted [9]). 


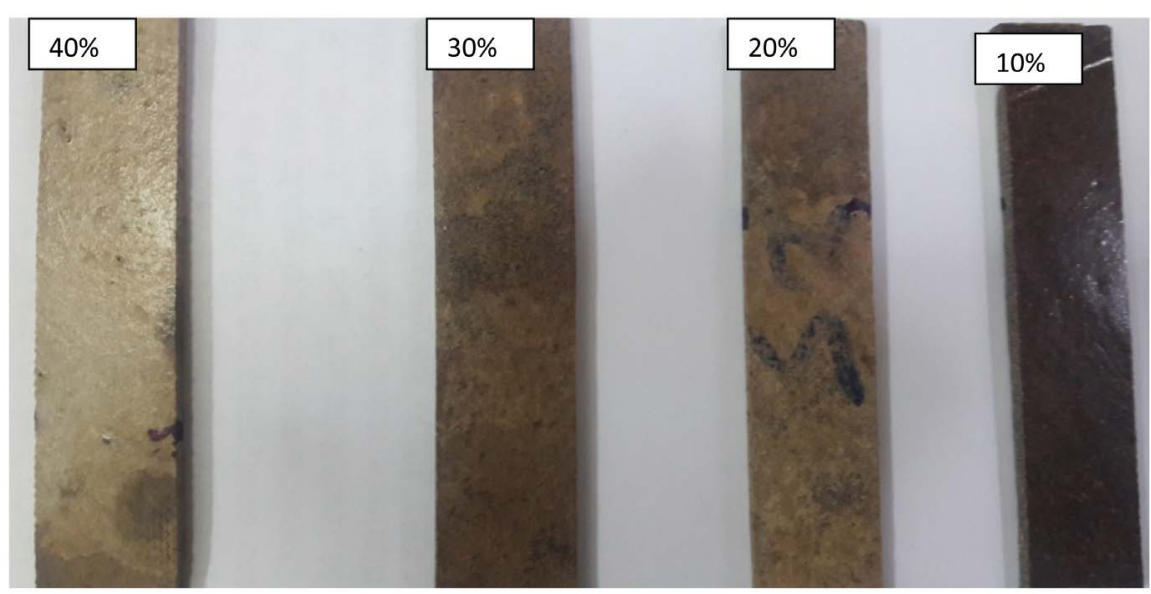

Figure 8. Visual images of 40\%, 30\%, 20\%, and 10\% fiber loading MHP-HDPE composites after 120 days burial in Municipal soil.

loadings led to increase the rate of biodegradation in municipal soils which influences the PLA composites. At the same time, water absorption within the composites enhances the microbial activities and development which help to start the biodegradation [27].

\subsection{Percentage Elongation}

The percentage elongations of the MHP-PLA composites after soil burial were depicted in Figure 9. There was better percentage elongation of MHP-PLA composites even after burial in municipal for 120 days at $20 \%$ fiber loading, then it decreased as the fiber loading increase. The findings revealed that percentage elongation of composites type decreased after soil buried in municipal soil. This was observed for $20 \%$ fiber loading of MHP-PLA composite which was $18.2 \%$ after buried in municipal soil and highest at $13.2 \%$ when compared to neat PLA of $7.1 \%$.

\subsection{SEM}

SEM micrographs of MHP-PLA fractured impact surface post soil burial. Figure 10(a) revealed the appearance of fiber agglomeration in a transverse direction and images (Figure 10(b) and Figure 10(c)) indicated fractured interface between fiber and matrix at the edge of the specimen. Figure 10(a) revealed fiber-matrix debonding attributes of MHP-PLA specimen post burial in municipal soil, whereas images Figure 10(c) and Figure 10(d) of the figure show fiber decay within the specimen. However, the micrographs of MHP-PLA composites post soil burial in municipal soil indicated sign of degradation. The images from Figures 10(a)-(c) also revealed appearances of fiber agglomeration and fiber-matrix debonding as well as fiber pull out. It was observed that there very slight difference between specimens buried in municipal soil for MHP-PLA composites. Further, Figures 11(a)-(d) prove micrograph of MHP-PLA composites (a) 10\% (b) 20\% (c) 30\% (d) 40\% fiber loadings of before soil burial in Municipal soil. Thus, composites defects such as fiber-matrix debonding, fiber agglomeration, fiber pull out and decay served as stress concentrators thereby affecting the mechanical properties of the composites. 


\section{MHP-PLA}

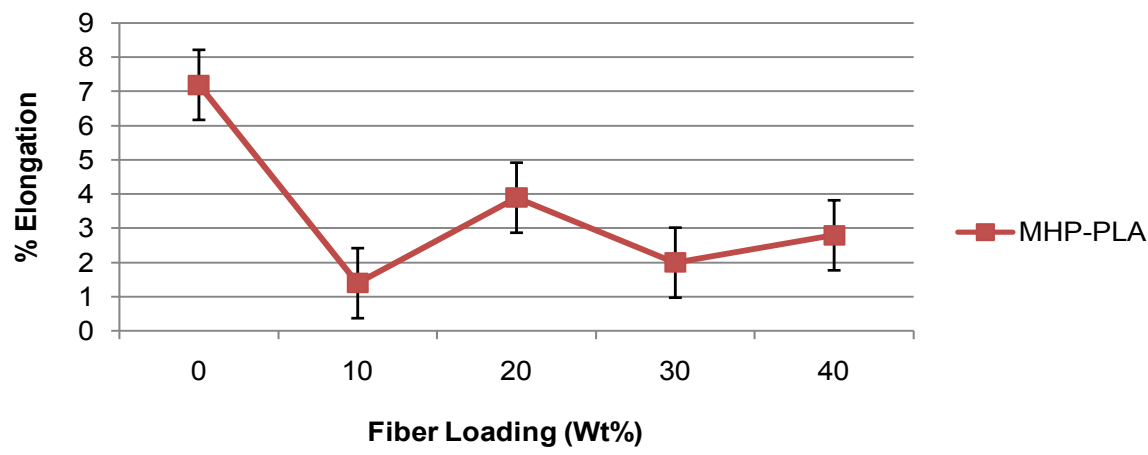

Figure 9. Elongation at break of MHP-PLA composites soil burial (Municipal soil).
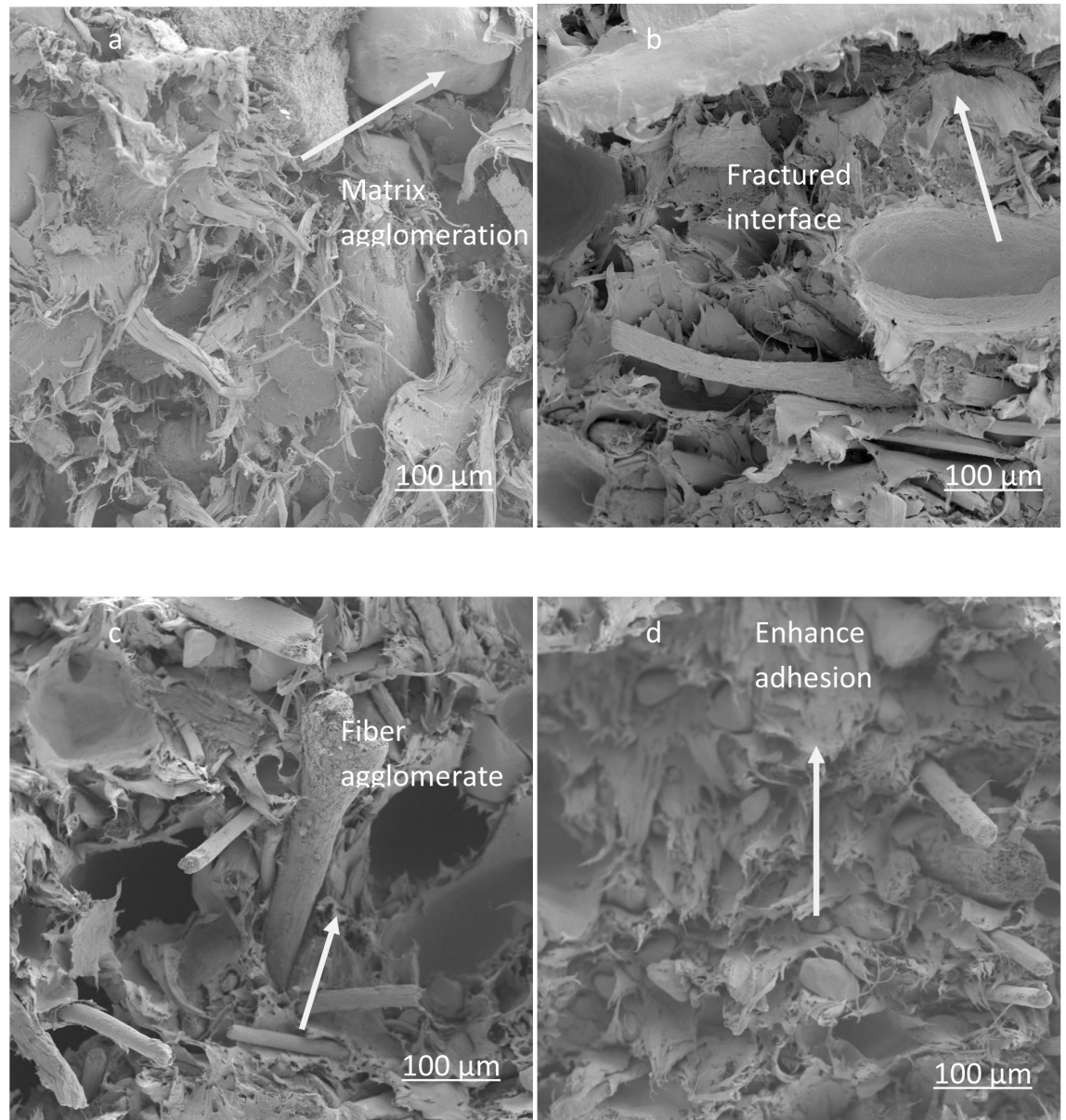

Figure 10. SEM micrographs showing microstructures of MHP-PLA composites (a) 10\% (b) $20 \%$ (c) $30 \%$ (d) $40 \%$ fiber loadings of after soil burial in Municipal soil.

\section{Conclusion}

Drawing from the experimental evidences, discussions and ideas presenting the conclusions can be drawn. The alkali treatment of the fiber improves the interfacial bonding between the fiber and matrix leading to increase in mechanical properties compared to untreated composites. The biodegradability of MHP-PLA 

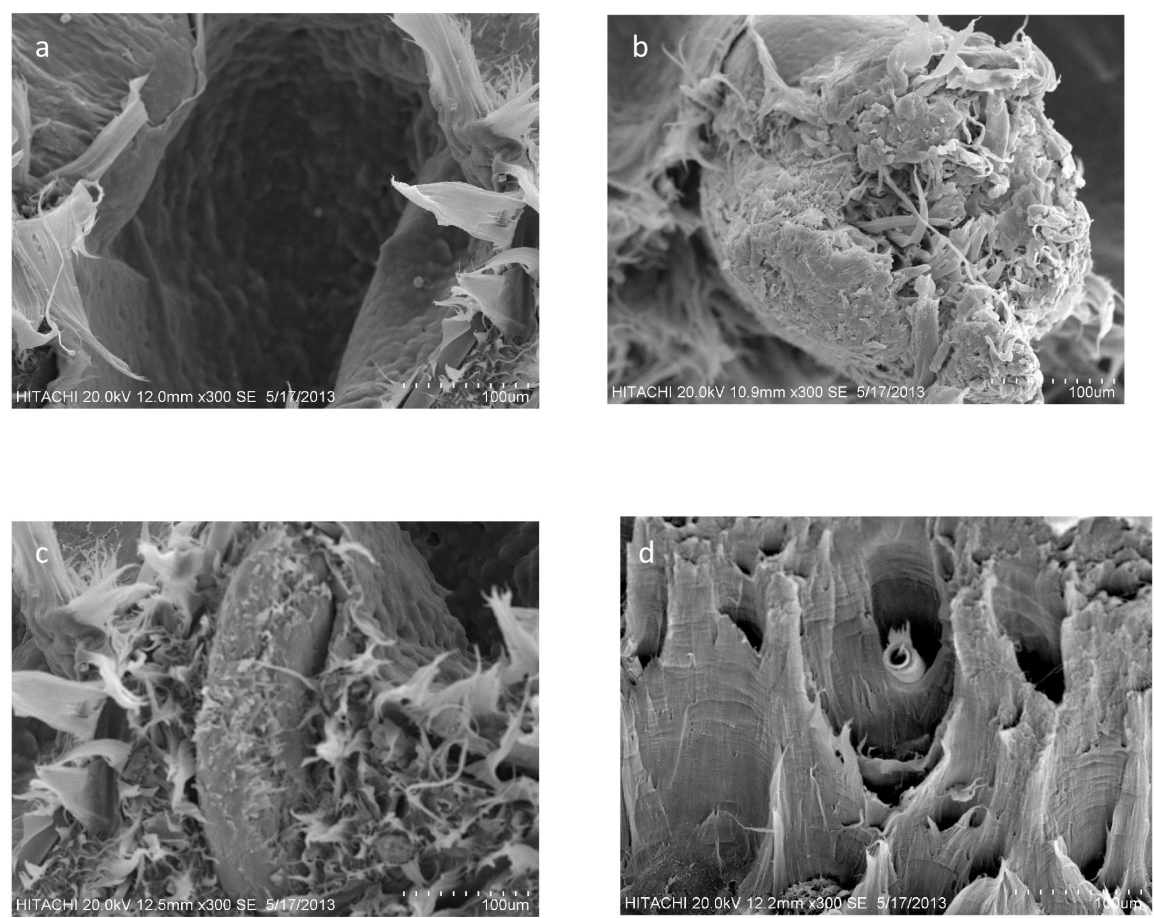

Figure 11. SEM micrographs showing microstructures of MHP-PLA composites (a) 10\% (b) $20 \%$ (c) $30 \%$ (d) $40 \%$ fiber loadings of before soil burial in Municipal soil.

composites was shown to be fibers and time durations dependent. The degradation of neat PLA composites buried in municipal soil indicated few differences as function of burial time. The MHP-PLA composites degrade faster but more pronounce in municipal soil. While it indicated slight dimensional changes showing degradation in municipal soil. The composites at $40 \%$ fiber loadings revealed the highest rate of decompositions in municipal soil with time as the main determining factor. The soil burial has significant effects on significant effects on mechanical properties of the composites compared to unburied composites.

\section{Conflicts of Interest}

The authors declare no conflicts of interest regarding the publication of this paper.

\section{References}

[1] Jumaidin, R., Sapuan, S.M., Jawaid, M., Ishak, M.R. and Sahari, J. (2017) Thermal, Mechanical, and Physical Properties of Seaweed/Sugar Palm Fibre Reinforced Thermoplastic Sugar Palm Starch/Agar Hybrid Composites. International Journal of Biological Macromolecules, 97, 606-615.

https://doi.org/10.1016/j.ijbiomac.2017.01.079

[2] Kiruthika, A.V. (2017) A Review on Physico-Mechanical Properties of Bast Fibre Reinforced Polymer Composites. Journal of Building Engineering, 9, 91-99.

https://doi.org/10.1016/j.jobe.2016.12.003 
[3] Merkel, K., Rydarowski, H., Kazimierczak, J. and Bloda, A. (2014) Processing and Characterization of Reinforced Polyethylene Composites Made with Lignocellulosic Fibres Isolated from Waste Plant Biomass Such as Hemp. Composites Part B: Engineering, 67, 138-144. https://doi.org/10.1016/j.compositesb.2014.06.007

[4] Sapuan, S.M. and Mansor, M.R. (2014) Concurrent Engineering Approach in the Development of Composite Products: A Review. Materials \& Design, 58, 161-167. https://doi.org/10.1016/j.matdes.2014.01.059

[5] Sain, M. and Panthapulakkal, S. (2006) Bioprocess Preparation of Wheat Fiber and Characterization. Industrial Crop Production, 23, 1-8. https://doi.org/10.1016/j.indcrop.2005.01.006

[6] Samper, M.D., Petrucci, R., Sánchez-Nacher, L., Balart, R. and Kenny, J.M. (2015) New Environmentally Friendly Composite Laminates with Epoxidized Linseed Oil (ELO) and Slate Fiber Fabrics. Composites Part B: Engineering, 71, 203-209. https://doi.org/10.1016/j.compositesb.2014.11.034

[7] Mahjoub, R., Yatim, J.M., Mohd Sam, A.R. and Hashemi, S.H. (2014) The Tensile Properties of Kenaf Fiber Due to Various Conditions of Chemical Fiber Surface Modification. Construction and Building Materials, 55, 103-133.

https://doi.org/10.1016/j.conbuildmat.2014.01.036

[8] Miller, S.A., Srubar Iii, W.V., Billington, S.L. and Lepech, M.D. (2015) Integrating Durability-Based Service-Life Predictions with Environmental Impact Assessments of Natural Fiber-Reinforced Composite Materials. Resources, Conservation and Recycling, 99, 72-83. https://doi.org/10.1016/j.resconrec.2015.04.004

[9] Shanshan, L., Yanhua, Z., Jiyou, G. and Haiyan, T. (2017) Biodegradation Behavior and Modelling of Soil Burial Effect on Degradation rate of PLA Blended with Starch and Wood Flour. Colloids and Surfaces B: Biointerfaces, 159, 800-808. https://doi.org/10.1016/j.colsurfb.2017.08.056

[10] Du, Y., et al. (2014) Fabrication and Characterization of Fully Biodegradable Natural Fiber-Reinforced Poly(lactic acid) Composites. Composites: Part B: Engineering, 56, 717-723. https://doi.org/10.1016/j.compositesb.2013.09.012

[11] Adhikiry, K.B., Pang, S. and Staiger, M.P. (2008) Dimensional Stability and Mechanical Behaviour of Wood-Plastic Composite Based on Recycling and Virgin High-Density Polypropylene (HDPE). Composites Part B: Engineering, 39, 807-815. https://doi.org/10.1016/j.compositesb.2007.10.005

[12] Babaei, I., Madanipour, M., Farsi, M. and Farajpoor, A. (2014) Physical and Mechanical Properties of Foamed HDPE/Wheat Straw Flour/Nanoclay Hybrid Composite. Composites Part B: Engineering, 56, 163-170. https://doi.org/10.1016/j.compositesb.2013.08.039

[13] Davoodi, M.M., Sapuan, S.M., Ahmad, D., Aidy, A., Khalina, A. and Jonoobi, M. (2012) Effect of Polybutylene Terephthalate (PBT) on Impact Property Improvement of Hybrid Kenaf/Glass Epoxy Composite. Materials Letters, 67, 5-7. https://doi.org/10.1016/j.matlet.2011.08.101

[14] Boopalan, M., Niranjanaa, M. and Umapathy, M.J. (2013) Study on the Mechanical Properties and Thermal Properties of Jute and Banana Fiber Reinforced Epoxy Hybrid Composites. Composites Part B: Engineering, 51, 54-57.

https://doi.org/10.1016/j.compositesb.2013.02.033

[15] Ridzuan, M.J.M., Abdul Majid, M.S., Afendi, M., Aqmariah Kanafiah, S.N., Zahri, J.M. and Gibson, A.G. (2016) Characterisation of Natural Cellulosic Fibre from Pennisetum purpureum Stem as Potential Reinforcement of Polymer Composites. Materials \& Design, 89, 839-847. https://doi.org/10.1016/j.matdes.2015.10.052 
[16] ASTM G160-12 (2012) Standard Practice for Evaluating Degradation and Microbial Susceptibility of Nonmetalic Materials by Soil Burial ASTM International.

[17] AS1289B1 (2012) Standard Association of Australia for Determination of Soil Moisture Content by Oven-Drying Methods AS Standard.

[18] Chuensangjuna, C., Pechyenb, C. and Sirisansaneeyakula, S. (2013) Degradation Behaviors of Different Blends of Polylactic Acid Buried in Soil. Energy Procedia, 34, 73-82. https://doi.org/10.1016/j.egypro.2013.06.735

[19] Maizatulnisa, O., Nor Azowa, I., Che Mohd, R., Nazarudin, Z. and Zahurin, H. (2012) Biodegradability Analysis of KBF Reinforced Poly(lactic acid) Biocomposites. Advanced Materials Research, 576, 434-437. https://doi.org/10.4028/www.scientific.net/AMR.576.434

[20] Kim, H.-S., Yang, H.-S. and Kim, H.-J. (2005) Biodegradability and Mechanical Properties of Agro-Flour-Filled Polybutylene Succinate Biocomposites. Applied Polymer Science, 97, 1513-1521. https://doi.org/10.1002/app.21905

[21] Ishiaku, U.S., Pang, W.S., Lee, W.S. and Ishak, A.M. (2002) Biodegradability and Mechanical Properties of Agro-Flour-Filled Polybutylene Succinate Biocomposites. European Polymer Material, 38, 393-403. https://doi.org/10.1016/S0014-3057(01)00125-2

[22] Tserki, V., Matzimos, P. and Panayiotou, C. (2006) Biodegradable Aliphatic Polyesters, Part II: Synthesis and Characterization of Chain Extended Poly(butylenes succinate-co-butylene adipate). Polymer Degradation Stability, 91, 367-372. https://doi.org/10.1016/j.polymdegradstab.2005.04.035

[23] Singh, G., Kaur, N., Bhunia, H., Bajpai, P.K. and Mandal, U.K. (2011) Degradation Behaviors of Linear Low-Density Polyethylene and Poly(Llactic Acid) Blends. Journal of Applied Polymer Science, 124, 1993-1998. https://doi.org/10.1002/app.35216

[24] Nourbakhsh, A., Ashori, A. and Kazemi Tabrizi, A. (2014) Characterization and Biodegradability of Polypropylene Composites Using Agricultural Residues and Waste Fish. Composites Part B: Engineering, 56, 279-283. https://doi.org/10.1016/j.compositesb.2013.08.028

[25] Oliveira, C., Cunha, F. and Andrade, C. (2010) Evaluation of Biodegradability of Different Blends of Polystyrene and Starch Buried in Soil. Macromolecular Symposium, 290, 115-120. https://doi.org/10.1002/masy.201050413

[26] Lucas, N., Bienaice, C., Belloy, C., Queneulie, M., Silvestre, F. and Nava-Saucedo, J.E. (2008) Polymer Degradation: Mechanisms and Estimation Techniques: A Review. Chemosphere, 73, 429-442. https://doi.org/10.1016/j.chemosphere.2008.06.064

[27] Alvarez, V.A., Ruseckaite, R.A. and Vázquez, A. (2006) Degradation of Sisal Fibre/Mater Bi-Y Biocomposites Buried in Soil. Polymer Degradation and Stability, 91, 3156-3162. https://doi.org/10.1016/j.polymdegradstab.2006.07.011

[28] Hammajam, A.A., Ismarrubie, Z.N. and Sapuan, S.M. (2014) Effect of Fiber Loading on the Mechanical Properties of Millet Husk Filled High Density Polyethylene Composites. Applied Mechanics and Materials, 564, 350-354.

https://doi.org/10.4028/www.scientific.net/AMM.564.350

[29] FAO (2017) Millet Production Index. http://www.fao.0rg/countryprofiles/index/en/NGA 